\title{
Mechanical properties of surface layer of unfilled polypropylene
}

\author{
David Manas $^{1, \mathrm{a}}$, Jozef Dobransky ${ }^{2}$ and Lenka Chvatalova ${ }^{1}$ \\ ${ }^{1}$ Tomas Bata University in Zlin, Nam. T.G.Masaryka 5555, Zlin, 760 01, Czech Republic \\ ${ }^{2}$ Technical University of Košice, Faculty of Manufacturing Technologies with a seat in Prešov, Department of Automobile and \\ Manufacturing Technologies, Štúrova 31, 08001 Prešov, Slovakia
}

\begin{abstract}
Using high doses of beta radiation for unfilled polypropylene (PP) and its influence on the changes of micromechanical properties of surface layer has not been studied in detail so far. The testing sapmles polypropylene (PP) were made by injection moulding technology and irradiated by high doses of beta radiation $(0,15$ and $33 \mathrm{kGy})$. The changes in the microstructure and micromechanical properties of surface layer were evaluated using WAXS and instrumented ultra nano-hardness test. The results of the measurements showed considerable increase in micromechanical properties (indentation hardness, indentation elastic modulus) when low doses of beta radiation are used.
\end{abstract}

\section{Introduction}

Polypropylene is a versatile, low cost, chemically stable and lightweight polymer, which offers attractive mechanical, electrical and thermal properties due to its relative higher degree of crystallinity. This is used in many applications such as radiation-sterilized medical and pharmaceutical components, food packaging materials and cosmetics [5]. A literature survey [6-11] indicates that effects of $14.89 \mathrm{MeV}$ electron irradiation on polyethylene and polystyrene in the dose range of 57.6-576 KGy showed a greater red shift in absorption edge of polyethylene as compared to polystyrene [6]. Whereas, the enhancement in the thermal properties, dielectric constant, dielectric loss and crystallinity of 2 $\mathrm{MeV}$ and $1.5 \mathrm{MeV}$ electron irradiated polypropylene has also shown considerable modifications $[7,8]$. However, more investigations are needed as far as the radiation energy, mode of energy deposition and energy densities are concerned. In particular, the effects of highenergy pulsed electron irradiation on mechanical Properties such as surface hardness and surface roughness of polypropylene needs more attention. Out of several types of radiations that can be used for radiation processing, high-energy electrons are of particular interest, especially for polymers, due to their high dose rates and consequently high-energy deposition in lesser time intervals. This not only achieves high process rates, but also allows crosslinking, as oxidation effects are relatively weak at the high dose rates. Moreover, electron beam irradiation also offers facility of easy control, maintenance of steady dose rate without any depletion and homogeneous energy deposition $[2,6,12]$.

The principle of the radiation process is the ability of the high energy radiation to produce reactive cationts, anoints and free radicals in the material. The industrial application of the radiation process (Figure 1) on polymer and composites includes polymerization, crosslinklinking and degradation. The radiation process involves mainly the use of either electron beam from electron accelerators or gamma radiation from Cobalt - 60 sources.

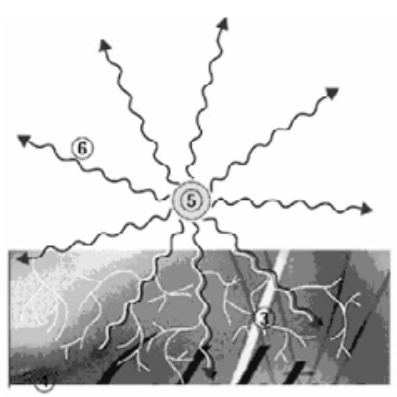

a)

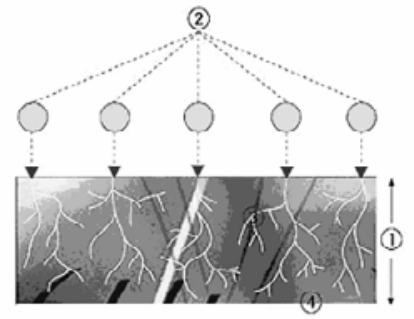

b)
Fig. 1. Design of Gamma rays (a) and Electron rays (b). a) 3 - secondary electrons, 4 - irradiated material, 5 encapsulated $\mathrm{Co}-60$ radiation source, 6 - Gamma rays

b) 1 - penetration depth of electron, 2 - primary electron, 3 secondary electron, 4 - irradiated materiál

The aim of this paper is to study the effect of ionizing radiation with different doses, on ultra nano-hardness of surface layer of polypropylene (PP) and compare these results with those of non-irradiated samples. The study is carried out due to the ever-growing employment of this type of polymer polypropylene (PP) [3-10].

\section{Experimental}

\subsection{Material and methods}

\footnotetext{
$\overline{{ }^{a} \text { Corresponding author: dmanas@ft.utb.cz }}$
} 
For this experiment PTS-Crealen EP-2300L1-M800; PTS Plastics Technologie Service, Germany (unfilled, iPP+TAIC, MFR $-230{ }^{\circ} \mathrm{C} / 2,16 \mathrm{~kg}-6 \mathrm{~g} / 10 \mathrm{~min}$ ) was used. The material already contained a special crosslinking agent TAIC - triallylisocyanurate (6 volume \%), which should enable subsequent cross-linking by ionizing $\beta$-radiation. Irradiation was carried out in the company BGS Beta Gamma Service GmbH \& Co, KG, Germany with the electron rays, electron energy $10 \mathrm{MeV}$, doses minimum of 0,15 and $33 \mathrm{kGy}$ on air the ambient temperature.

The samples (Figure 2) were made using the injection molding technology on the injection moulding machine Arburg Allrounder 420C. Processing temperature 245$295{ }^{\circ} \mathrm{C}$, mold temperature $85^{\circ} \mathrm{C}$, injection pressure 80 $\mathrm{MPa}$, injection rate $45 \mathrm{~mm} / \mathrm{s}$. [7-17]

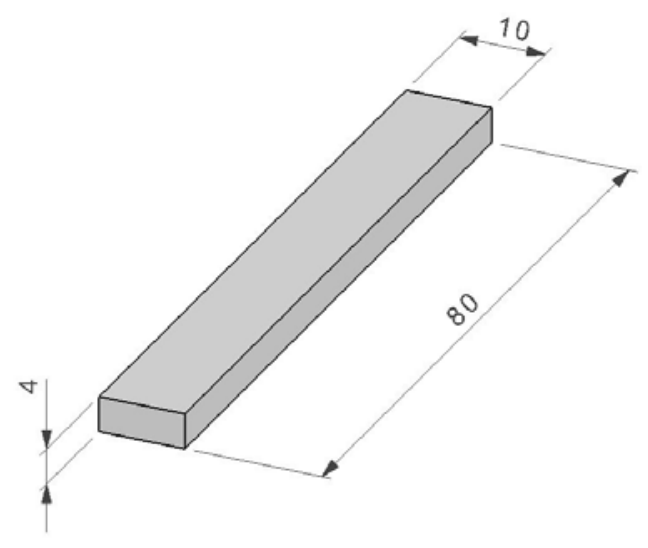

Fig. 2. Dimension of sample.

\subsection{Ultra nano-hardness test}

Nano-indentation test was done using a Ultra Nanoindenation Tester (UNHT) (Fig. 5), CSM Instruments (Switzerland) according to the CSN EN ISO 14577. Load and unload speed was $1000 \mu \mathrm{N} / \mathrm{min}$. After a holding time of $90 \mathrm{~s}$ at maximum load $500 \mu \mathrm{N}$ the specimens were unloaded. The specimens were glued on metallic sample holders (Fig. 2). [7-17]

$$
\mathrm{H}_{\mathrm{IT}}=\mathrm{F}_{\max } / \mathrm{A}_{\mathrm{p}}
$$

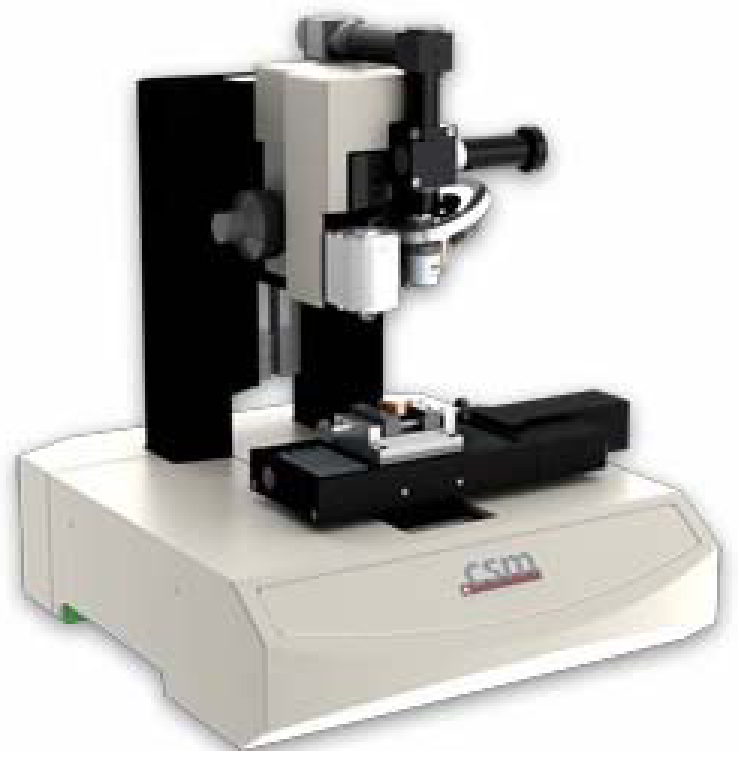

Fig. 3. Ultra nano-indentation tester.

\subsection{Wide-angle X-ray scattering}

Wide-angle X-ray diffraction patterns were obtained using a PANalytical X'Pert PRO X-ray diffraction system (Netherlands). The $\mathrm{CuK} \alpha$ radiation was $\mathrm{Ni}$ filtered. The scans $\left(4.5^{\circ} 2 \Theta / \mathrm{min}\right)$ in the reflection mode were taken in the range $5-30 \circ 2 \Theta$. The sample crystallinity $(\mathrm{X})$ was calculated from the ratio of the crystal diffraction peaks and the total scattering areas. Crystall size L100 of $\alpha$ most intensive peak at 100 was calculated using Scherrer equation. As a standard "perfect" crystal terephthalic acid with the peak at $2 \Theta=$ $17.4^{\circ}$ and the half maximum breadth $0.3^{\circ} 2 \Theta$ was chosen [7-17].

\section{Results and discussion}

The development of micromechanical properties of irradiated polypropylene (PP) was characterized by the instrumented test of ultra nanohardness (indentation hardness $\mathrm{H}_{\mathrm{IT}}$ ), as can be seen in Figure 4. The highest values of indentation hardness $(68 \mathrm{MPa})$ were found on polypropylene (PP) irradiated with radiation dose of 15 $\mathrm{kGy}$ radiation dose, while the lower value of indentation hardness $(56 \mathrm{MPa})$ was measured at $33 \mathrm{kGy}$ radiation dose. The lowest values (49 MPa) of indentation hardness were found on non-irradiated polypropylene (PP). The increase of microhardness at $15 \mathrm{kGy}$ radiation dose was by $38 \%$ compared to the non-irradiated polypropylene (PP). 


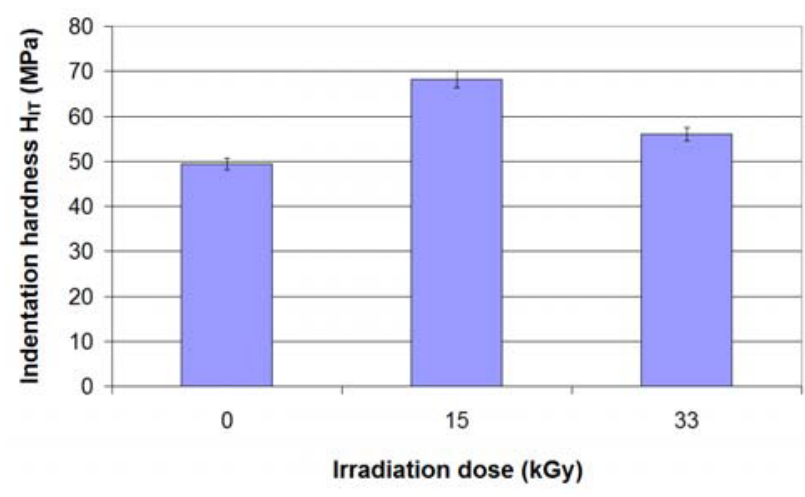

Fig. 4. Indentation hardness $\mathrm{H}_{\mathrm{IT}}$ vs. irradiation doses.

Similar development was recorded for microstiffness of specimens represented by the elastic modulus of indentation $\left(\mathrm{E}_{\mathrm{IT}}\right)$ illustrated in Figure 5. The results of measurements show clearly that the highest values of microstiffness were measured on the polypropylene (PP) $(1.02 \mathrm{GPa})$ irradiated with radiation dose of $15 \mathrm{kGy}$, while the lower values were reached in polypropylene (PP) irradiated by $33 \mathrm{kGy}$ dose $(0.82 \mathrm{GPa})$. The lowest values $(0.77 \mathrm{MPa})$ of microstiffness were found on nonirradiated polypropylene (PP). A significant increase of microstiffness $(32 \%)$ was recorded at the radiation dose of $15 \mathrm{kGy}$ compared to the non-irradiated polypropylene (PP).

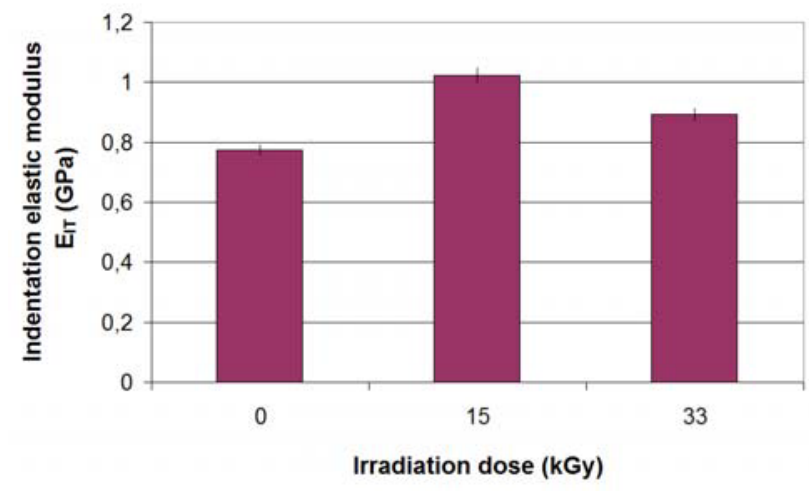

Fig. 5. Indentation elastic modulus $\mathrm{E}_{\mathrm{IT}} \mathrm{vs.}$ irradiation doses.

Other important material parameters obtained during the micro-hardness test were elastic and plastic deformation work. The mechanical work $\mathrm{W}_{\text {tota }} \mathrm{l}$ induced by the indentation is only partly consumed as plastic deformation work $\mathrm{W}_{\text {plast }}$. During the removal of the test force the remaining part is set free as work of the elastic reverse deformation $\mathrm{W}_{\text {elast }}$.

Very important values were found for indentation creep. For materials which creeps as polymers, a basic calculation of that creep can be measure during a pause at the maximum force. The creep is the relative change of the indentation depth when the test force is kept constant measured by instrumented test of microhardness showed (Figure 6) that the lowest creep values were measured on non-irradiated polypropylene (PP) $(10 \%)$, while the highest creep value was found in polypropylene (PP) irradiated by $15 \mathrm{kGy}$ dose (13\%). The creep increased by
$35 \%$ as a result of radiation, which represents a considerable decrease of surface layer resistance.

When applying $\beta$-radiation the structure of polypropylene undergoes loss and then a grow of the crystalline phase. It can be assumed that the size of individual crystals will correspond with the loss of crystalline phase (crystalline value $X$ calculated lay in the range 45-67\%). Cross-linking occurs in the remaining noncrystalline part which has a significant influence on the mechanical properties of the surface layer. The greatest size (Table 1) of crystalline phase was found in the case at the radiation dose of $15 \mathrm{kGy}(67 \%)$. The smaller size of crystalline phase was found in the case at the radiation dose of $33 \mathrm{kGy}(54 \%)$. On the contrary the smallest size of crystalline phase was measured at nonirradiated $(45 \%)$. Its influence on the mechanical behavior is insignificant.

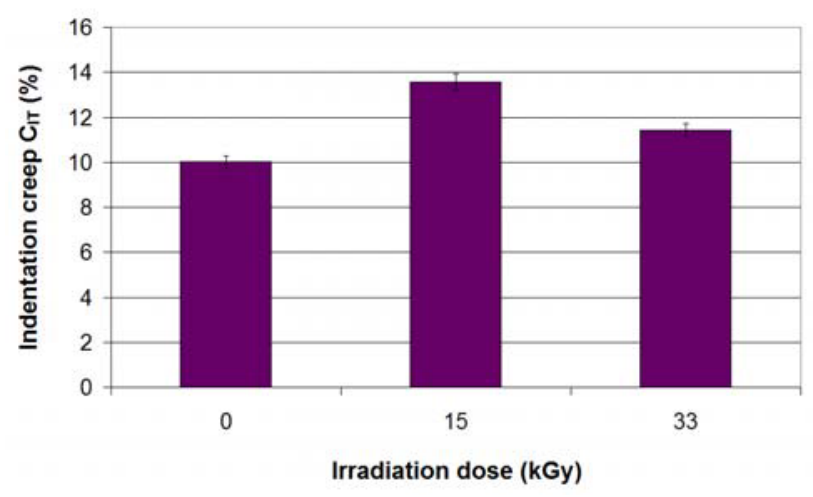

Fig. 6. Indentation creep $C_{\mathrm{IT}}$ vs. irradiation doses.

The highest values of elastic deformation work were obtained for non-irradiated polypropylene (PP). The highest values of plastic deformation work were obtained for polypropylene (PP) irradiated with radiation dose of $15 \mathrm{kGy}$. The lowest values of Wel, were obtained for polypropylene (PP) irradiated with dose of $15 \mathrm{kGy}$. Radiation of specimens caused lower values of plastic deformation work which is in Figure 7.

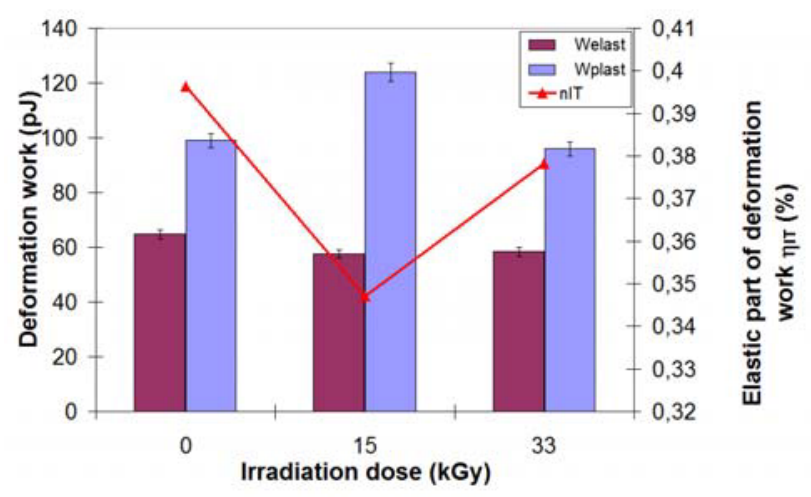

Fig. 7. Deformation work vs. irradiation dose.

Higher radiation dose does not influence significantly the micro-hardness value. An indentation hardness 
increase of the surface layer is caused by irradiation cross-linking of the tested specimen. A closer look at the micro-hardness results reveals that when the highest radiation doses are used, micro-hardness decreases which can be caused by radiation induced degradation of the material.

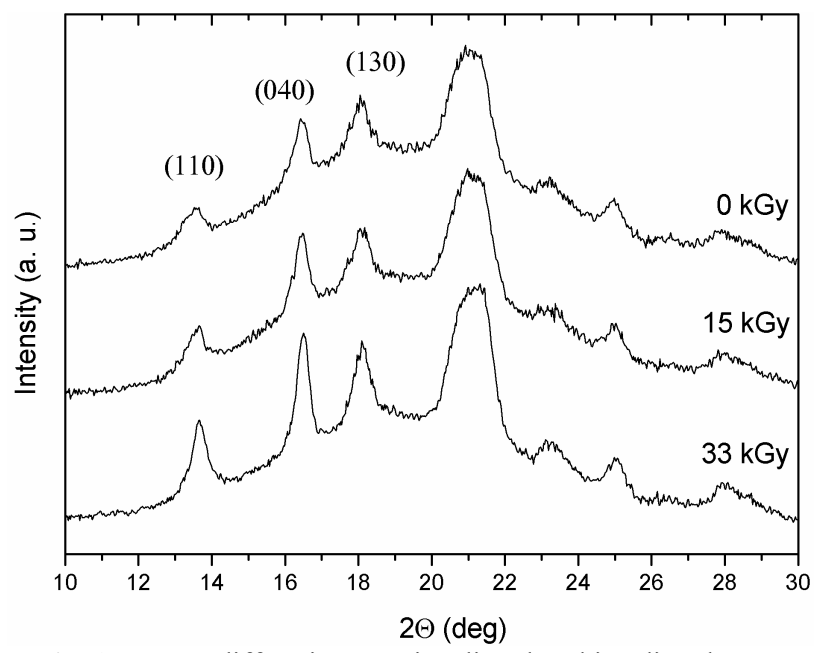

Fig. 8. X- ray diffraction non-irradiated and irradiated PBT.

The figure 8 shows typical X-ray diffraction spectrum of the non-irradiated and irradiated polypropylene (PP). There is an apparent presence of $\alpha$-phase in the nonirradiated specimen. The greatest grow of $\alpha$-phase is seen at the radiation dose of $15 \mathrm{kGy}$ (Figure 8).

Table 1. X-ray diffraction of non-irradiated and irradiated PP.

\begin{tabular}{|c|c|}
\hline Sample & X X-ray, $\%, \pm \mathbf{1 \%}$ \\
\hline 0 kGy & 45 \\
\hline 15 kGy & 67 \\
\hline 33 kGy & 54 \\
\hline
\end{tabular}

\section{Conclusion}

The experimental study deals with the effect of modification of the surface layer by irradiation crosslinking on the properties of the surface layer of polypropylene (PP). Polypropylene (PP) was modified by beta irradiation at doses of 0,15 and $33 \mathrm{kGy}$. The changes of micromechanical properties were found at the radiation dose of $15 \mathrm{kGy}$ for indentation hardness which decreased by $38 \%$ compared to the non-irradiated polypropylene (PP). Improvement of mechanical properties in micro and macro scale of radiated polypropylene (PP) has a great significance also for industry. The modified polypropylene (PP) shifts to the group of materials which have considerably better properties. Its micromechanical properties make polypropylene (PP) ideal for a wide application in the areas where higher resistance to wear, scratch are required.

\section{Acknowledgment}

This paper is supported by the internal grant of TBU in Zlin No. IGA/FT/2017/010 funded from the resources of specific university research and by the Ministry of Education, Youth and Sports of the Czech Republic within the National Sustainability Programme project No. LO1303 (MSMT-7778/2014) and also by the European Regional Development Fund under the project CEBIATech No. CZ.1.05/2.1.00/03.0089. Special thanks also to Dr. Michal Danek (BGS Beta Gamma Service GmbH \& Co, KG, Germany) for his kind assistance during sample preparation.

\section{References}

1. Dj. Gheysari, Eur. Polym. J. 37 (2001) 295-302, (2001)

2. K. Makuuchi, S. Cheng. Wiley, Hoboken, 2011.

3. J.G. Drobny, Elsevier, Oxford, 2013.

4. D. Dobrota, Energy Procedia, 100, 1160-1166, (2015)

5. G. Zamfirova, V. Gaydarov, T. Zaharescu, L. G. Silva. Chemicke Listy, 104, 283-286, (2010)

6. D. Manas, M. Hribova, M. Manas, M. Ovsik,M. Stanek, Thin Solid Films, 530, 49-52,(2013)

7. O. Uzuna, U. Kölemena, S. Çelebi, N. Güçlü, Journal of the European Ceramic Society. 25, 969977, (2005).

8. W. C. Oliver, G. M. Pharr. J Mater Res, 7. (6) 1564-1583, (1992)

9. E. Ragan, P. Baron, J. Dobránsky. Advanced Materials Research 383-390, 2813-2818, (2012).

10. H. Wang, L. Xu, R. Li, J. Hu, M. Wang, G. Wu, Radiation Physics and Chemistry, 125, 41-49, (2016)

11. J. Dobránsky, L. Běhálek, P. Baron, Key Engineering Materials, 669, 36-43, (2016)

12. Dobransky, J., Běhalek, L., Baron, P., Kočiško, M., Simkulet, V., Vojnova, E., Briančin, J. Metalurgija, 55 (3), pp. 449-452, (2016)

13. Dobránsky, J., Kočiško, M., Baron, P., Simkulet, V., Běhálek, L., Vojnová, E., Nováková Marcinčinová, L. Metalurgija, 55 (3), pp. 477-480, (2016)

14. J. Čop, L. Fojtl, O. Bílek, V. Pata, Manufacturing Technology, 16 (2), pp. 334-338, (2016)

15. Singh, P. Kishore, M. Singh, A. Srivastava, Radiation Effects and Defects in Solids, 170 (10), 845-853, (2015)

16. S. Kashyap, D. Datta, International Journal of Plastics Technology, 19 (1), 1-18, (2015)

17. S. Zhang, R. Dubay, M. Charest, Expert Systems with Applications, 42 (6), 2919-2927, (2015) 